\title{
Identification and Prioritization of Criteria Used for Selecting Protected Areas in Forest Ecosystems Case Study: Iran's Hyrcanian Forests
}

\author{
Naghmeh Sharifi (Corresponding author) \\ MSc graduated of Environmental Science \\ No.32, Golestan $4^{\text {th }}$, Velenjak 22, Tehran, Iran
}

Tel: 98-912-440-3800Ｅ-mail: naghmehsh2005@yahoo.com

\author{
Afshin Danehkar \\ Associate Professor, Faculty of Natural Resources \\ University of Tehran, PO Box 4111 Karaj, Iran \\ Tel: 98-912-309-4861Ｅ-mail: danehkar@nrf.ut.ac.ir \\ Vahid Etemad \\ Assistant Professor, Faculty of Natural Resources \\ University of Tehran, PO Box 4111, Karaj, Iran
}

Tel: 98-261-222-8016 E-mail: etemad@nrf.ut.ac.ir

\section{Beytollah Mahmoudi}

MSc graduated of Natural Resources, Iran

Tel: 98-913-005-6076 E-mail: Beytollahmahmoudi@gmail.com

$\begin{array}{lc}\text { Received: October 19, } 2011 & \text { Accepted: November 14, } 2011 \quad \text { Published: December 1, } 2011 \\ \text { doi:10.5539/enrr.v1n1p189 } & \text { URL: http://dx.doi.org/10.5539/enrr.v1n1p189 }\end{array}$

\begin{abstract}
In this study, first of all 5 core criteria and 26 sub-criteria to select protected patches in Iran's natural ecosystems were derived. During the next step to elect appropriate criteria and sub-criteria to chose protected patches in Hyrcanian forest areas, these criteria being organized in a Delphi Questionnaire were presented to protection experts and finally the results extracted from Criteria-importance diagram based on two parameters of importance percentage and importance rank of under study criteria showed that there are 5 core criteria including habitat, species, social aspects, economical aspects, and managerial aspects and 18 sub-criteria including uniqueness of habitat, vulnerability of habitat, representativeness of habitat, importance of habitat, landscape, water resources, species diversity, species damage, species population, species protection-degree, compatibility, historical and cultural importance, importance in national economy, dependence for local economy, legal support, threat factors, research and monitoring and training respecting importance to be used to elect protected patches in Caspian forest ecosystems in Iran.
\end{abstract}

Keywords: Protected area, Forest conservation, Hyrcanian forest ecosystem, Criteria, Multi-Criteria evaluation, Delphi method

\section{Introduction}

Increasing growth of world population and need to occupy more spaces to fulfill humans' requirements caused to extensively invade natural resources and genetic reserves. This hasty invasion to natural resources destroys or seriously threatens biological diversity all over the world (Zhao, 2006). Among natural ecosystems, forest ones 
are supposed as biologic treasures of human which are necessary to be protected for next generations (Bayat \& Madjnounian, 1988; Dengue, 2006). Forest ecosystems are vast areas covered by trees, shrubs, and grass species which along with wild animals form a kind of unity of herbal and animal lives and they are able to preserve their natural sustainability under the effect of continental and soil factors (Marvi Mohajer, 2007). Iran's biological-environmental crisises are extremely complicated. Their effective factors include populate increase, desertification, destruction of ecosystems, dissemblance of life diversity, enhancement of urban areas, destruction of forests, air pollution, water pollution, and soil erosion (Mosadeg, 2005). Among Iran's forests, north forests are continuously being threatened by several destructive factors including illegal wood logging, forest exploitation, existing livestock, conversion of forest areas into agricultural fields, collection of fuel wood, and etc. (Hosseini \& Akbarinia, 2003). Regarding the threats before Iran's natural ecosystems particularly forest resources, attributing some parts of these invaluable ecosystems to protection application may be useful for preserving them for next generations and therefore promote the goals of protection of such resources which include restoring local herbal and animal populate, sufficient protection of habitats to protect them from being more devastated, reducing habitat destruction, and ecological maintenance and restoration (Jones et al., 2006). Iran's quadruplet areas under protection are National Park, protected area, national natural areas, and wild life shelter covering $7.7 \%$ (12.7 million hectares) of whole area of the country. Among the mentioned regions, the largest area is allocated for 111 protected regions. These regions include $58.11 \%$ of protected areas, (Environment Protection Organization, 2008).

\subsection{Identifying method}

Therefore the election of protected areas shall be able not only to promote the network of protected areas of the country but also to provide the best choices from different natural ecosystems. As there are no reliable scientific method to choose protected areas in natural ecosystems of Iran, and since common procedures of other countries have been designed based on their own ecological and environmental circumstances and so they lack specific properties being appropriate to Iran's protected areas, it is necessary to take a more practical action in this regard by identifying general methods, programs and principles of protection of such areas. Because as long as it deals with electing several areas of nature, being equipped with an appropriate method one may completely distinguish these areas (Kiabi \& Zehzad, 1987). In this order, making use of qualitative and quantitative criteria is a common and tested method not only to identify sensitive and vulnerable habitats but also to choose protected areas and this fact necessitates applying expertise in this regard (Danekar \& Madjnounian, 2004). Obviously the criteria presented by relevant International Organizations are posed just as generic guides which cannot be extended to specific and different circumstances of all countries of the world. Even, due to lack of information, some of these criteria may be unusable in some countries (Madjnounian, 2000). One of main reasons to provide generic criteria is wide range of biophysical and social, economical, and cultural differences and each country shall be able to specialize and match these criteria with their particular circumstances regarding its own natural-human properties (Madjnounian, 2000). For this purpose, in this research we aim to choose appropriate protection criteria and specify their percentage and importance level in order to choose protected patches in forest ecosystem in north of Iran.

\subsection{Criteria functions}

The mentioned criteria have two main functions. First, they assess the areas' competency in protection station and second, they make one able to rank competent areas with respect to priority in election process (Madjnounian, 2004).

\subsection{Existing relevant criteria}

From applied criteria in protected area election process we can indicate the followings:

- Habitat \& wildlife assessing criteria to choose areas encompass two major groups of criteria to assess wildlife and habitat for each different sub-criterion and indexes have been introduced (Kiabi \& Zehzad, 1987).

- Guide criteria to determine protected habitats comparing each other encompass size, integration, shape and relation (WCS, 1980).

- Carleton-Ray criteria to choose marine national parks include two groups of ecologic criteria and the criteria which are associated with scientific and applied significance (Charlton-Ray, 1970).

- Marine protected area election criteria which encompass ecologic, economical, social, practical, and regional criteria (Salm \& Price, 1995).

- Coastal and marine protected areas planning criteria include the criteria associated with habitat and species (Salm \& Clark, 1982). 
- Global cultural and natural heritage election criteria include the criteria being used to elect cultural heritages and the criteria for electing natural heritages (Global Heritage Conservation Convention, 2008).

- Criteria for evaluating ecologic power of the land for protection, human use of resources, shortage of scientific researches in the region, sensitivity to dangers (erosion, fall, slime, flood, severe aridity, or pollutions), species biodiversity, and unique habitat and scarce species, swelled geologic and/or geomorphologic structures, remarkable natural beauty, virgin nature, abundance of significant beasts, wildlife migration passage and corridor, hydromorphic and vulnerable soil, having invaluable historical or national heritage, slope more than $70 \%$, and high demographic value (Makhdoum, 2000).

- Coastal and marine areas assessment criteria for specifying coastal and marine protected areas of Iran are biogeography, virginity, uniqueness, dependency, habitat, habitat diversity, habitat size, habitat integration, aqua culture, aquatic diversity, aqua protection value, birds, sea turtles, sea mammals, protection history, human dependence, economical significance, recreation, training, research and monitoring and threatens have been introduced (Danekar \& Madjnounian, 2004).

- IMO criteria for choosing marine protected areas which encompass ecologic criteria, economical criteria, cultural criteria, social criteria, and practical and educational criteria (IMO, 2001).

- The criteria for choosing biosphere reserves are representativeness, naturalness, life diversity, and effectiveness (Tundi Agardy, 1989).

- IUCN criteria for choosing marine protected areas are geographical life significance, ecologic significance, naturalness, economical significance, social significance, scientific significance, national or global significance, practicability, and feasibility (IUCN, 1999).

\subsubsection{Criteria for forest resource protection management}

Some criteria which play roles in forest resource protection management, either in direct or indirect manner, are as follows:

- Forest sustainable management criteria in Iran include ecosystem, economical, and social criteria (Zahedi, Amiri, 2005).

- Near East criteria for sustainable management of forests include size or limits of forest resources, preserving life diversity in forest areas, health, survivability and preserving the entirety (integrity) of forest, function and production capacity of forest ecosystem, protection and environmental responsibilities, protection and development of economical-social responsibilities and legal framework (FAO \& UNEP, 1999).

- Wood International Organization criteria for sustainable management of forests in tropical areas include empowerment of circumstances for forest sustainable management, protecting forest resources, situation and health of forest ecosystem, circulation of forest product, biologic diversity, water and soil, and economical, social, and cultural aspects (ITTO, 2005).

\section{Methodology}

\subsection{Steps of Method}

In this study we made use of Delphi modulated method which is a multi-criteria method. In this method according to comparative studies 5 core criteria including habitat, species, social aspects, economical aspects, and managerial aspects as well as 26 sub-criteria including habitat uniqueness, habitat vulnerability, habitat significance, landscape, water resources, species diversity, damage to species, species populate, species significance, species protection level (degree of conservation), compatibility, social acceptability, safety, public health, cultural and historical importance, significance level in national economy, dependence for local economy, legal support, threat factors, recreation, availability, feasibility, protection history, research \& monitoring, and training for choosing protected patches in natural ecosystems were identified and categorized. Diagram 1 illustrates conceptual model of relation between criteria and sub-criteria.

In continue experts polling questionnaire (Delphi Questionnaire) and Criteria significance diagram were used to determine significance level of criteria and sub-criteria identified to select protected patches in forest ecosystems and finally the ideas of 22 experienced experts and connoisseurs were collected. The respondents were asked to specify criteria and sub-criteria significance level and each respondent selected a significance level out of 5 significance levels (inconsiderable, of low significance, significant, of high significance, and of very high significance) which bearing different weights $(1,3,5,7,9)$. Hence, the number of choices for every significance level was supposed as point index of that significance level. Then the point of the weight dedicated to every criterion was calculated and the percentage of the point obtained out of total obtainable weighted point for every 
criteria and sub-criteria was specified. Also, weighted average of significance level for every criterion was separately calculated and considered for final judge. In weighting of criteria, it was cared that sum of weights for every criteria (according to significance level) had not to excess 10 . In fact, weights of criteria were taken within 0-10 range. Each significance level presented a domain of the weight of a criterion. Thus:

- $\quad$ Point 1 for inconsiderable level presenting domain of 0-2

- $\quad$ Point 3 for of low significance level presenting domain of 2-4

- $\quad$ Point 5 for significant level presenting domain of 4-6

- $\quad$ Point 7 for of high significance level presenting domain of 6-8

- Point 9 for of very high significance level presenting domain of 8-10

Therefore, modulated weight index of every criterion was calculated by Eq. 10 divided by sum of weights of the criteria and then it was multiplied by the criteria weight number. Modulated weight was multiplied by each criterion point to obtain weighted point of that criterion.

In order to obtain significance percentage of each criterion, sum of weighted point (respecting modulated weight) was divided by maximum obtainable weighted point. Maximum obtainable weighted point in its turn was obtained by multiplying maximum expected point (in this study 22 which is total respondents) by maximum modulated weight (10). Accordingly by dividing total sum of weighted points for every criterion by maximum obtainable point, the proportion of points taken in every criterion was calculated and then presented in percentage (the result was multiplied by 100).

In the next step, weighted average of significance level for each criterion was determined by summation of the products of multiplication of point by weight (significance level) divided by total sum of points (equaling total respondents, here 22) and the result was taken as significance level of each criterion.

Finally, by plotting of criteria significance diagram in which the horizontal axis is significance percentage and the vertical one is significance level of each criterion, it was judged about the possibility of accepting the identified criteria. This diagram was separated in 4 parts as per half numerical value of each vertical and horizontal axis and in order to choose the best criteria, the criteria bearing more than one half of numerical value of every axis were used.

\subsection{Mathematical relations}

The above method has the following mathematical relations:

$x_{i}$ : Primitive weight

$n$ : The number of people voted a significance level (point)

$\frac{10}{\sum x_{i}}$ : Modulated weight index

$\sum x_{i}$

$\left(y_{i}\right)=\frac{10}{\sum x_{i}} \times x_{i}:$ Modulated weight

$\left(z_{i}\right)=y_{i} \times n:$ Weighted point

$\frac{\sum z_{i}}{A}=\frac{\sum z_{i}}{220} \times 100:$ Criteria significance percentage

$A$ : Maximum obtainable point

$\frac{\sum\left(x_{i} \times n\right)}{N}:$ Criteria significance level

$N$ : Total respondents

\section{Results}

\subsection{Core Criteria}

5 core criteria of protection were habitat, species, social aspects, economical aspects, and managerial aspects which have been evaluated for forest ecosystem of Iran. According to the findings on habitat criteria, all protection experts categorized this criterion as significant, high significant and very high significant criteria in selecting protected patches of forest ecosystems and as per performed calculations, significance percentage for this criterion stood at $51.43 \%$ and its significance level lay within very high domain (8.23). About species criterion, similarly all experts categorized this criterion as significant, high significant and very high significant 
criterion and as per performed calculations significance percentage for this criterion stood at $50.62 \%$ and its significance level lay within very high domain (8.09).

Social aspects criterion was categorized by $68.18 \%$ of respondents as significant criterion in selecting protected patches in forest ecosystems. $31.82 \%$ of respondents attributed high significance to it and no expert knew it a very significant criterion. In general, significance percentage for this criterion stood at $46.98 \%$ and its significance level lay within significant domain (5.64).

Economical aspects criterion was categorized by $13.64 \%$ of respondents as inconsiderable criterion in selecting protected patches in forest ecosystems while $86.36 \%$ knew it as significant, of high significance, and of very high significance criterion of which $4.55 \%$ voted to its high significance. According to performed calculations, the significance percentage for this criterion respecting obtainable point stood at $23.48 \%$ and its significance level according to its weighted average lay within significant domain (5.64).

Regarding managerial aspects criterion more than half of experts voted to its high and very high significance in the process of selecting protected patches in forest ecosystems of the country and according to performed calculations, the significance percentage for this criterion respecting obtainable point stood at $35.5 \%$ and its significance level according to its weighted average lay within "of highly significance" domain (7.45). (Table 1)

Diagram 2 represents the significance of the criteria. As it can be seen from this diagram, habitat criterion bears the highest significance percentage and economical aspects criterion bears the lowest significance percentage. Significance diagram of protection criterion in forest environment (diagram 3) with respect to significance percentage and significance level of protection criterion indicates that economical aspects criterion lacks primitive conditions to be accepted to be engaged in selecting protected patches in forest ecosystems. This situation in itself does not prevent us from using the mentioned criterion; but final judgment will be made just after investigating the significance diagram of the sub-criterion.

\subsection{Sub criteria}

As mentioned earlier 26 sub-criteria were evaluated for protection of forest ecosystems of Iran among which uniqueness gained a significance percentage of $40.29 \%$ and lay with "of very high significance" domain, while vulnerability with $35.49 \%$, representativeness with $33.12 \%$, and habitat significance with $30.08 \%$ were categorized under "of high significance" title. Landscape and water resources lay within "significant" domain respectively with $23.48 \%$ and $23.27 \%$ of significance. Diversity with $38.11 \%$ and protection level with $30.74 \%$ of significance were categorized as "of very high significance" sub-criterion while damage with $22.35 \%$, population with $20.84 \%$, and species importance with $20.07 \%$ of significance lay in "significant" domain. Social sub-criterion all lay within "significant" category which are compatibility, cultural and historical importance, safety, social acceptability, and public health respectively with $24.25 \%, 23.49 \%, 22.72 \%, 20.07 \%$, and $18.18 \%$ of significance. Out of two economical sub-criteria, "dependence for local economy" with $29.01 \%$ lay within "of high significance" domain and after that, "importance in national economy" with $23.11 \%$ lay within "significant" domain. Finally out of managerial sub-criteria, legal support with $31.61 \%$ and threat factors with $29.43 \%$ fell in "of high significance" domain while research \& monitoring, training, protection history, feasibility, availability, and recreation respectively with $27.26 \%, 27.26 \%, 20.27 \%, 19.13 \%, 17.45 \%, 17.09 \%$ lay within "significant" domain. (Table 2)

Diagram 4 provides the reader with the significance percentages of the sub-criteria. As you may find out of this diagram, uniqueness sub-criterion and subsequently diversity sub-criterion bear the highest significance percentages while recreation bears the lowest significance percentage for selecting protected patches in forest ecosystems. Diagram 5 shows the significance of protection sub-criteria in forest ecosystem. This diagram indicates that species importance, recreation, availability, feasibility, protection history, safety, public health, and social acceptability lack sufficiency to be engaged in selecting protected patches in forest ecosystems and therefore they will be omitted. Consequently, since its sub-criteria both were accepted, economical criterion will remain as a core criterion to choose protected patches in forest ecosystems.

\section{Discussion and Conclusion}

Taking decision that which criteria and sub-criteria shall be chosen and which shall be omitted for selecting protected patches in forest ecosystem (specifically Hyrcanian forests) was made according to significance percentage and significance level of each criterion. Accordingly 5 criteria and 18 sub-criteria will be used to choose protected patches in Hyrcanian forests as the following:

(1) Habitat criterion (its sub-criteria are landscape, representativeness, uniqueness, habitat importance, vulnerability, and water resources) 
(2) Species criterion (its sub-criteria are species diversity, population, protection level, and damage)

(3) Social criterion (its sub-criteria are cultural \& historical importance and compatibility)

(4) Economical criterion (its sub-criteria are dependence for local economy and importance for national economy)

(5) Managerial criterion (its sub-criteria are research \& monitoring, training, threat factors and legal support)

Also, it is possible to determine the priority of the above criteria and sub-criteria by diagrams 2 and 4 . According to diagram 2, the priority of the criteria is as follows: habitat, species, social aspects, managerial aspects and economical aspects. Similarly, diagram 4 provides the priority of the sub-criteria as follows: habitat uniqueness, species diversity, habitat vulnerability, habitat representativeness, legal support, species' protection level, habitat importance, threat factors, dependence for local economy, research \& monitoring, training, compatibility, cultural \& historical importance, landscape, water resources, importance in national economy, damage and population (Edward \& Porter-Bolland, 2008).

Therefore, out of the criteria of selecting protected patches, 8 sub-criteria including species importance, recreation, availability, feasibility, protection history, safety, public health, and social acceptability were not applied to the process of selecting protected patches of Hyrcanian forests. However, applying protection criteria in other natural ecosystems like mountain, steppes, desert, marsh, and shore ecosystems needs separate studies. Different experts emphasized on the conformity of applied criteria with the ecosystem. Majid Makhdoum clearly indicates in his book, Foundation of Logistics of Land, that in applying ecologic models to evaluate environment, the models mentioned for Iran appear to be just a generic guide and it is required that a special model for evaluation within Iran's ecologic models framework is organized depending the place under study, the identified data, and the objective to use the land (Makhdoum, 2006, Luciana et al., 2011). Rykiel also clearly indicates that in order to make a model to evaluate environment power, it is required to pay special attention to the objective, the criteria, and the structure of the model (Rykiel, 1996, Grace, 2006). Obviously, the priority and the weights of selected criteria are calculated and determined through hierarchical analysis.

\section{References}

Agardi, T. (1989). A guide to planning reservoir of biosphere, in Henric Madjnounian and Jamshid Mansouri, 2005, Application of the concept of lifesphere reservoirs in coastal and marine areas, Environment Protection Organization, Tehran, 46-51.

Carleton, R. (1970). Essential criteria for selecting national sea parks, in Henric Madjnounian, 2000, Guidebook of Identifying Criteria associated with International Core Marshes, Iran protected areas: Fundamentals and tactics to protect parks and areas, appendix 33, Environment Protection Organization, Tehran, 458-459.

Danehkar, A. B. Riazi, \& L. Davar. (2008). Guide of Environmental Sensitivity Index (ESI) Mapping presented by National Oceanic \& Atmospheric Administration (NOAA), page 24.

Danehkar, A. \& Madjnounian, H. (2004). Proposed criteria to evaluate coastal and marine areas to determine protected coastal and marine areas in Iran, Evaluating Caspian shore protected areas: a Case Study, Environment Quarterly: $30^{\text {th }}$ year, issue 35 (Fall 2004), 9-32.

Edward, A. \& Porter-Bolland, L. (2008) is community-based forest management more effective than protected areas?: A comparison of land use/land cover change in two neighboring study areas of the Central Yucatan Peninsula, Mexico. Forest Ecology and Management,256(11).1971-1983.

Evans, M.I. (1994). Important bird areas in the Middle East. Bird life International.

FAO. (1999). Practical Guidelines for the implementation of criteria and indicators for sustainable forest management in the Near East Region. United Nations Environmental Program. Regional Office for the Near East, Cairo.

Grace B. (2006). The rise of protected area policy in the Philippine forest policy: An analysis from the perspective of Advocacy Coalition Framework (ACF). Forest Policy and Economics. 9(2).162-178.

IMO/MEPC 46/23. (2001). Guidelines for the identification and design nation of particularly sensitive sea areas. Website: www.imo.org.

ITTO. (2005). Revised ITTO Criteria and Indicators for the Sustainable Management of Tropical Forests including Reporting Format. ITTO Policy Development Series No 15.Yokohama, Japan. 
IUCN. (1994). Levels of Red Content, in Henric Madjnounian, Guidebook of Identifying Criteria associated with International Core Marshes, Iran protected areas: Fundamentals and tactics to protect parks and areas, appendix 24, Environment Protection Organization, Tehran, 411-429.

IUCN. (1994). IUCN Red List Categories. Prepared by the IUCN Species Survival Commission. IUCN, Gland, Switzerland.

IUCN/WCPA. (1999). Guidelines for Marine Protected Areas. Edited \& coordinated by Graeme Kelleher.

Kiabi, B., \& B. Zahzad. (1987). Criteria for Selecting Areas based on Protection Ecologic Power, in Henric Madjnounian, 2000, Iran's protected areas: Fundamentals and tactics to protect parks and areas, appendix 22, Environment Protection Organization, Tehran, 404-407.

Luciana, A. Ellis, R. Guariguata, I. \& Reyes-Garcia, V. (2011). Community managed forests and forest protected areas: An assessment of their conservation effectiveness across the tropics. Forest Ecology and Management. In Press, Corrected Proof in Science Direct.

Madjnounian, H. Kiabi, H., Goshtasb, H. \& J, Mansouri. (2004). Proposed criteria to evaluate protection station of marshes of Iran, Environment Quarterly, $28^{\text {th }}$ year, issue 33 (Spring 2004), 75-89.

Madjnounian, H. (2000). Guide for determining environmental special areas based on protection ecologic power model, in Henric Madjnounian, 2000, Iran's protected areas: Fundamentals and tactics to protect parks and areas, appendix 95, Environment Protection Organization, Tehran, 735-736.

Madjnounian, H. (2000). Protected Areas \& National Parks (Values \& Functions), Publish Center of Environment Protection Organization, page 480.

Makhdoum, M. (2000). Evaluation Model of Ecologic Power for Protection, in Henric Madjnounia, 2000, Iran's protected areas: Fundamentals and tactics to protect parks and areas, appendix 91, Environment Protection Organization, Tehran, 695-696.

Mosadegh, A. (2005). Environmental Crisises in Iran, Forest \& Park Journal, issue 68-69 (Fall and Winter 2005), 98-99.

Ramsar Convention. (1990). Guidebook of Identifying Criteria associated with International Core Marshes, in Henric Madjnounian, 2000, Iran's protected areas: Fundamentals and tactics to protect parks and areas, appendix 9, Environment Protection Organization, $4^{\text {th }}$ Conference of Member Countries, Tehran, 335-349.

Salm, R.V., \& A.Price. (1995). Selection of Marine Protected Areas: Principles of Techniques for Management. Edited by Susan Gubby. Chapman and Hall, London.

Salm, R.V., \& Clark, J.R. (1984). Marine and Coastal Protected Areas: A guide for planners and managers. IUCN, Gland, Switzerland.

UNESCO World Heritage Centre, (2008). Operational Guidelines for the Implementation of the World Heritage Convention.p:158-160. http://whc.unesco.org/archive/opguide08-en.pdf.

WCS, (1980). Guide of determining protected habitats in comparison to each other, in Henric Madjnounian, 2000, Iran's protected areas: Fundamentals and tactics to protect parks and areas, appendix 25, Environment Protection Organization, Tehran, 440-440.

Zahedi, A., \& Qavam, D.(2005).Criteria and Indices Recognition and Election and Necessary Evaluation for Environmental and Social Sustainability in Forest Ecosystems (Case Study on Golband and Kheiroudkenar Forests), Environment Organization.34p. 
Table 1. Calculating significance percentage and significance level of protection criteria

\begin{tabular}{|c|c|c|c|c|c|c|c|}
\hline Criterion & $\begin{array}{c}\text { Point } \\
\text { (n) }\end{array}$ & $\begin{array}{c}\text { Primitive } \\
\text { Weight (xi) }\end{array}$ & $\begin{array}{l}\text { Modulated } \\
\text { Weight (yi) }\end{array}$ & $\begin{array}{l}\text { Weighted } \\
\text { Point(zi) }\end{array}$ & Sum & $\begin{array}{l}\text { Significance } \\
\text { Percentage }\end{array}$ & $\begin{array}{c}\text { Significance } \\
\text { Level }\end{array}$ \\
\hline \multirow{5}{*}{ Habitat } & 0 & 1 & 0 & 0 & \multirow{5}{*}{113.15} & \multirow{5}{*}{$51.43 \%$} & \multirow{5}{*}{$\begin{array}{c}8.23 \\
\text { of very high } \\
\text { significance }\end{array}$} \\
\hline & 0 & 3 & 0 & 0 & & & \\
\hline & 0 & 5 & 0 & 0 & & & \\
\hline & 4 & 7 & 4.38 & 17.52 & & & \\
\hline & 17 & 9 & 5.63 & 95.63 & & & \\
\hline \multirow{5}{*}{ Species } & 0 & 1 & 0 & 0 & \multirow{5}{*}{111.36} & \multirow{5}{*}{$50.62 \%$} & \multirow{5}{*}{$\begin{array}{c}8.09 \\
\text { of high } \\
\text { significance }\end{array}$} \\
\hline & 0 & 3 & 0 & 0 & & & \\
\hline & 0 & 5 & 0 & 0 & & & \\
\hline & 10 & 7 & 4.38 & 43.8 & & & \\
\hline & 12 & 9 & 5.63 & 67.56 & & & \\
\hline \multirow{5}{*}{$\begin{array}{l}\text { Social } \\
\text { Aspects }\end{array}$} & 0 & 1 & 0 & 0 & \multirow{5}{*}{103.36} & \multirow{5}{*}{$46.98 \%$} & \multirow{5}{*}{$\begin{array}{c}5.64 \\
\text { significant }\end{array}$} \\
\hline & 0 & 3 & 0 & 0 & & & \\
\hline & 15 & 5 & 4.17 & 62.55 & & & \\
\hline & 7 & 7 & 5.83 & 40.81 & & & \\
\hline & 0 & 9 & 0 & 0 & & & \\
\hline \multirow{5}{*}{$\begin{array}{c}\text { Economical } \\
\text { Aspects }\end{array}$} & 0 & 1 & 0 & 0 & \multirow{5}{*}{51.66} & \multirow{5}{*}{$23.48 \%$} & \multirow{5}{*}{$\begin{array}{c}5.64 \\
\text { significant }\end{array}$} \\
\hline & 3 & 3 & 1.25 & 3.75 & & & \\
\hline & 10 & 5 & 2.08 & 20.8 & & & \\
\hline & 8 & 7 & 2.92 & 23.36 & & & \\
\hline & 1 & 9 & 3.75 & 3.75 & & & \\
\hline \multirow{5}{*}{$\begin{array}{c}\text { Managerial } \\
\text { Aspects }\end{array}$} & 0 & 1 & 0 & 0 & \multirow{5}{*}{78.09} & \multirow{5}{*}{$35.50 \%$} & \multirow{5}{*}{$\begin{array}{c}7.45 \\
\text { of high } \\
\text { significance }\end{array}$} \\
\hline & 0 & 3 & 0 & 0 & & & \\
\hline & 3 & 5 & 2.38 & 7.14 & & & \\
\hline & 11 & 7 & 3.33 & 36.63 & & & \\
\hline & 8 & 9 & 4.29 & 34.32 & & & \\
\hline
\end{tabular}


Table 2. Calculating significance percentage and significance level of protection sub-criteria

\begin{tabular}{|c|c|c|c|}
\hline Criteria & Sub-Criteria & Percentage of Importance & Degree of Importance \\
\hline \multirow{6}{*}{ Habitat } & uniqueness & $40.29 \%$ & Of very high significance \\
\hline & vulnerability & $35.49 \%$ & Of high significance \\
\hline & Landscape & $23.48 \%$ & Significant \\
\hline & water resources & $23.27 \%$ & Significant \\
\hline & representativeness & $33.12 \%$ & Of high significance \\
\hline & habitat significance & $30.08 \%$ & Of high significance \\
\hline \multirow{5}{*}{ Species } & protection level & $30.74 \%$ & Of high significance \\
\hline & Diversity & $38.11 \%$ & Of high significance \\
\hline & damage & $22.35 \%$ & Significant \\
\hline & species importance & $20.07 \%$ & Significant \\
\hline & population & $20.84 \%$ & Significant \\
\hline \multirow{5}{*}{ Social Aspects } & $\begin{array}{l}\text { cultural and historical } \\
\text { importance }\end{array}$ & $23.49 \%$ & Significant \\
\hline & compatibility & $24.25 \%$ & Significant \\
\hline & safety & $22.72 \%$ & Significant \\
\hline & social acceptability & $20.07 \%$ & Significant \\
\hline & public health & $18.18 \%$ & Significant \\
\hline \multirow{2}{*}{$\begin{array}{c}\text { Economical } \\
\text { Aspects }\end{array}$} & dependence for local economy & $29.01 \%$ & Of high significance \\
\hline & importance in national economy & $23.11 \%$ & Significant \\
\hline \multirow{8}{*}{$\begin{array}{l}\text { Managerial } \\
\text { Aspects }\end{array}$} & legal support & $31.61 \%$ & Of high significance \\
\hline & threat factors & $29.43 \%$ & Of high significance \\
\hline & research \& monitoring & $27.27 \%$ & Significant \\
\hline & training & $27.26 \%$ & Significant \\
\hline & protection history & $20.27 \%$ & Significant \\
\hline & feasibility & $19.13 \%$ & Significant \\
\hline & availability & $17.45 \%$ & Significant \\
\hline & recreation & $17.09 \%$ & Significant \\
\hline
\end{tabular}




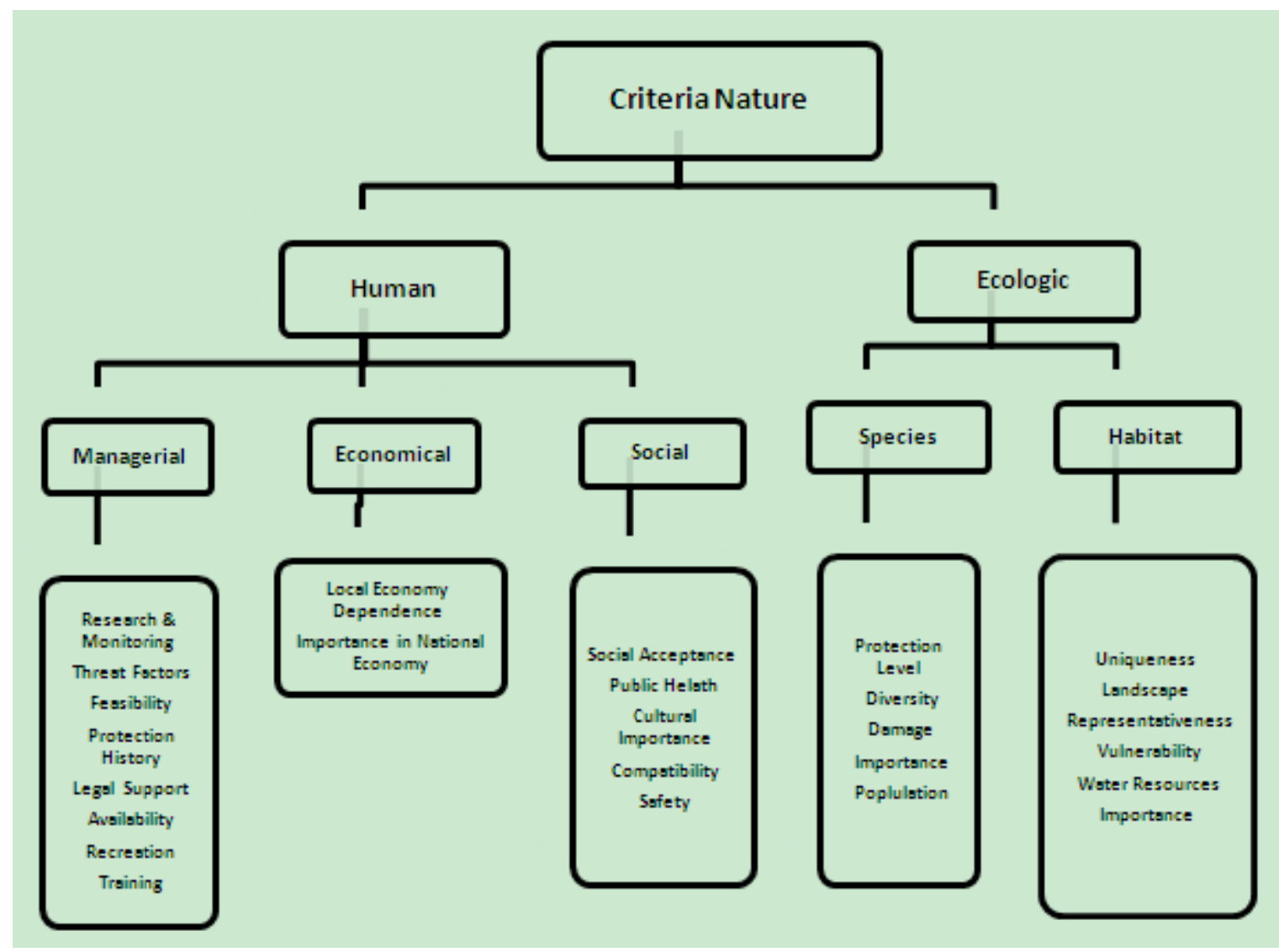

Figure 1. Hierarchy of criteria and sub-criteria used for selecting protection criteria

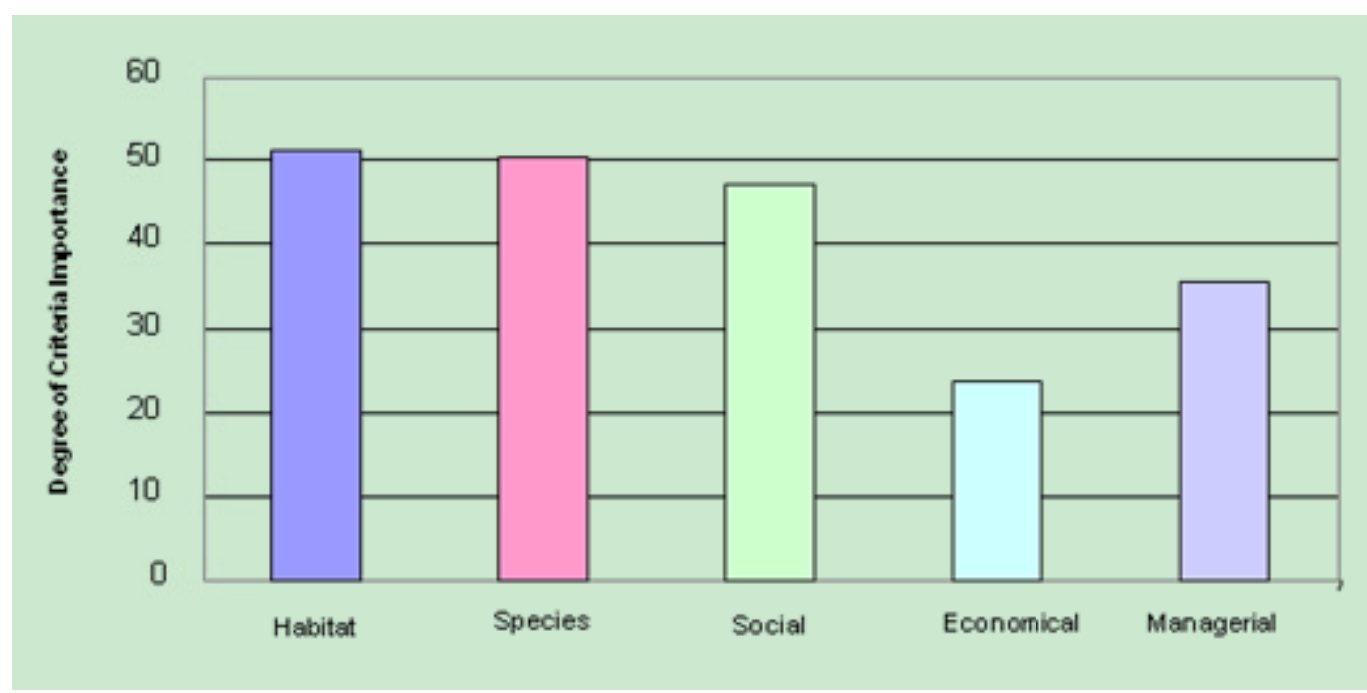

Figure 2. Percentage of importance of protection patches selection criteria in forest ecosystem 


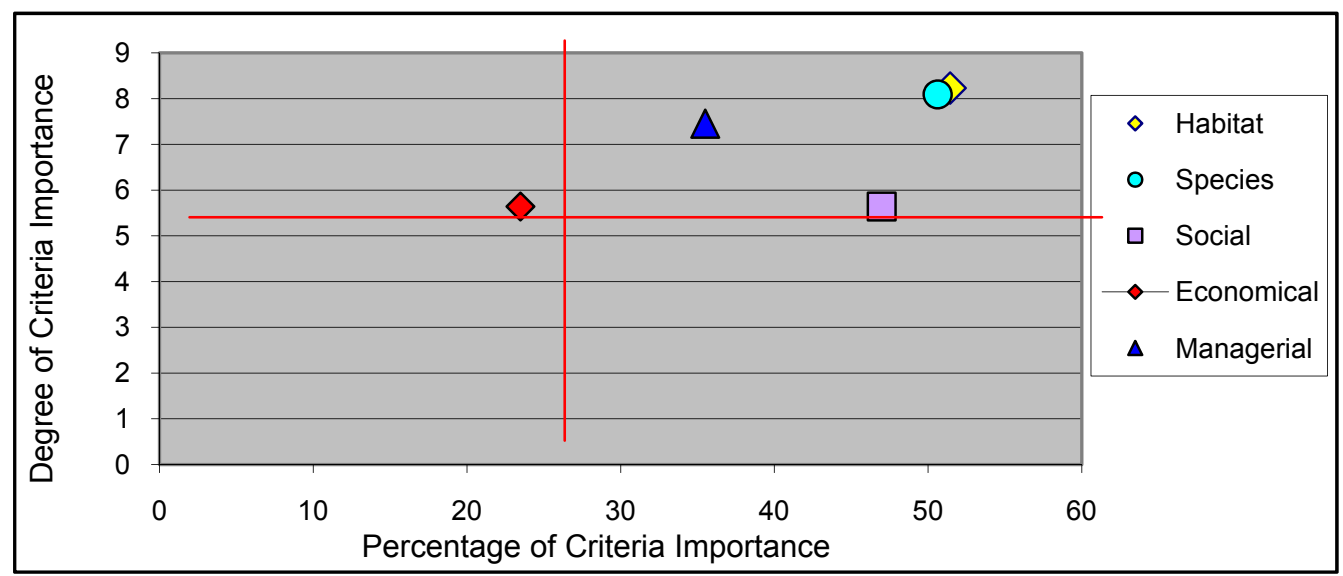

Figure 3. Percentage \& Degree of importance of protection patches selection criteria in forest ecosystem

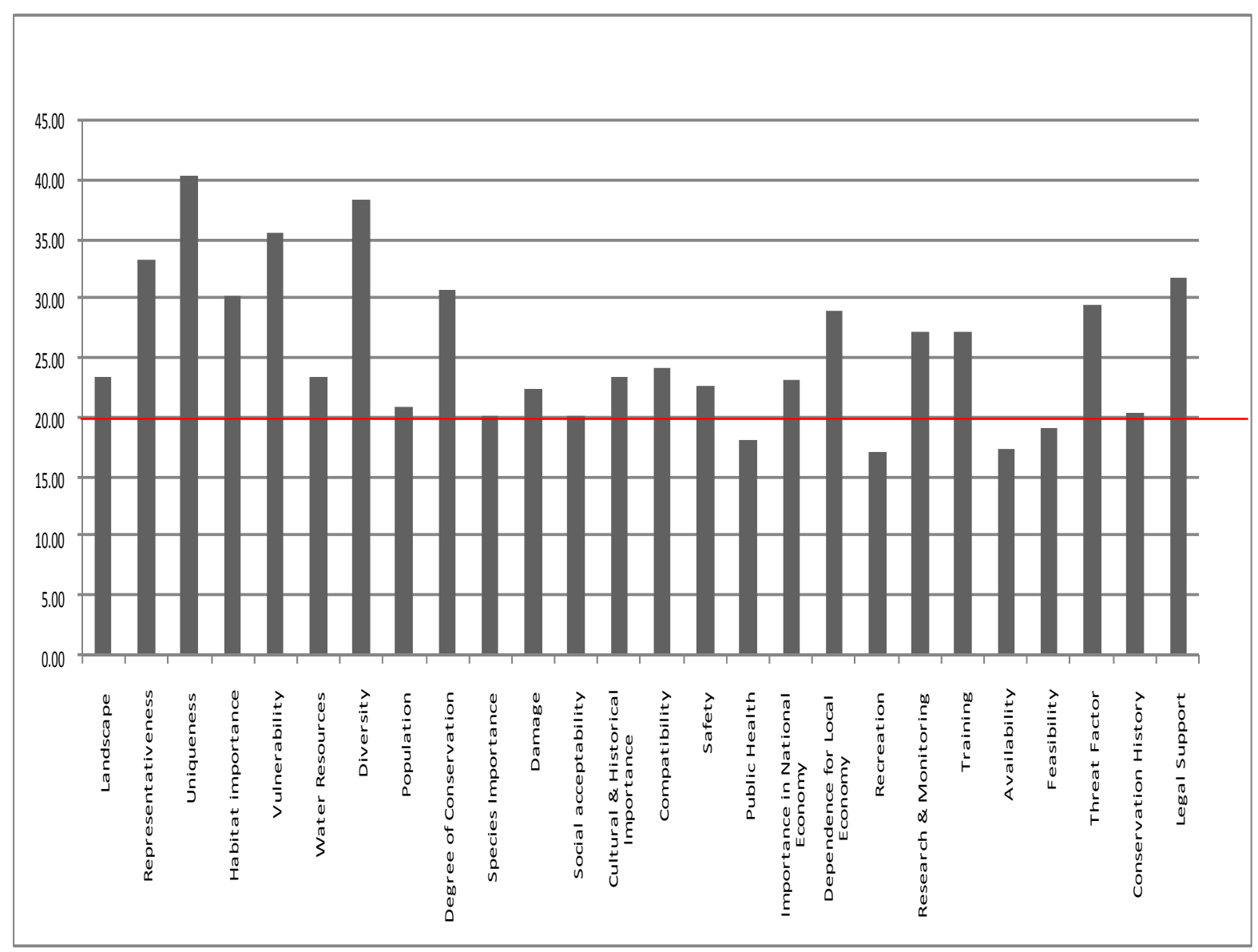

Figure 4. Percentage of importance of protection patches selection sub-criteria in forest ecosystem 


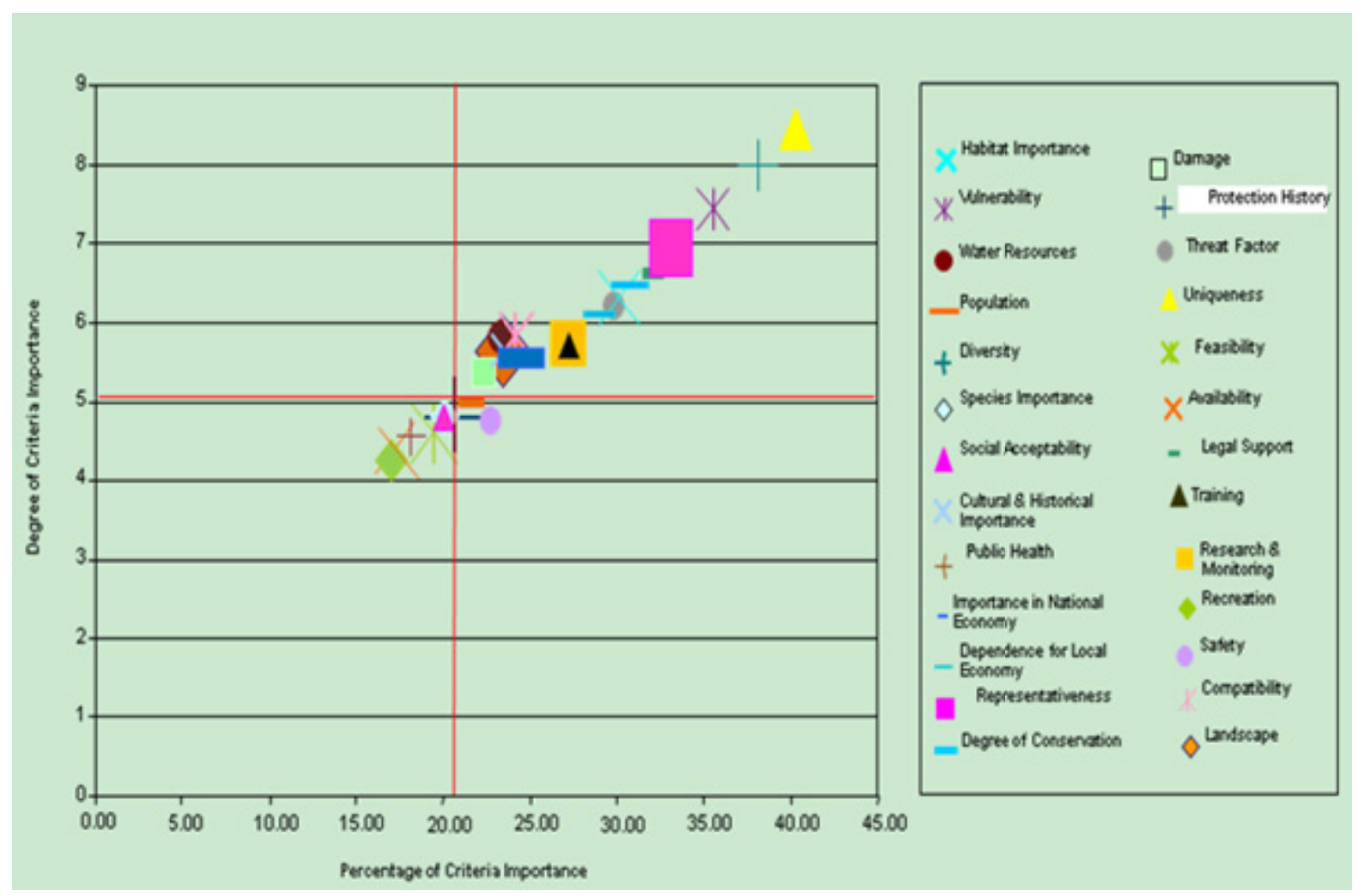

Figure 5. Percentage \& Degree of importance of protection patches selection sub-criteria in forest ecosystem 